\title{
ANALISIS DATA TIME SERIES DAN VCR KEPADATAN LALU LINTAS (STUDI KASUS: JALAN ADISUCIPTO DEPAN AMBARUKMO PLAZA)
}

\author{
Arief Rachma Wibowo, Indah Soesanti, \& Widyawan \\ Universitas Gadjah Mada \\ e-mail: arief.rachma.w@mail.ugm.ac.id
}

\begin{abstract}
Traffic density or commonly known as jamming is a situation where the buildup of vehicles in a particular road segment, this could be caused by several factors, including the number of vehicles that are in the road. The data source of this research result is directly generated from Dinas Perhubungan DIY The time series data analysis is used to predict the number of vehicles during the day and VCR analysis here to address the road conditions.Based on time series data analysis using trend methods, the number of motorcycle go down at 12.30 until 14.40. Based on VCR analysis, the number of vehicle reach the peak at 15.30 until 17.00. Condition at that time is very bad (class $F$ ).
\end{abstract}

Keywords: VCR, Traffic, Time Series

\begin{abstract}
ABSTRAK
Kepadatan lalu lintas atau biasa dikenal dengan istilah kemacetan merupakan kondisi dimana terjadinya penumpukan kendaraan disuatu ruas jalan tertentu, hal ini bisa saja disebabkan oleh beberapa faktor, antara lain jumlah kendaraan yang berada dalam ruas jalan tersebut. Sumber data dari riset ini langsung diperoleh dari Dinas Perhubungan DIY. Analisis data time series digunakan untuk meramalkan jumlah kendaraan pada siang hari dan analisis VCR disini untuk klasifikasi kondisi jalan tersebut. Berdasarkan analisis data time series menggunakan metode trend, data jumlah motor yang melalui Jalan Adisucipto pada pukul 12.30-14.40 cenderung mengalami penurunan. Berdasarkan analisis VCR, jumlah kendaraan mencapai puncaknya pada pukul 15.30-17.00 dan termasuk pada kelas F (sangat butuk), yaitu kondisi arus dipaksakan, kecepatan rendah, volume diatas kapasitas dan antrian panjang (macet).
\end{abstract}

Kata kunci: VCR, Lalu Lintas, Time Series

\section{PENDAHULUAN}

Perkembangan teknologi dari waktu ke waktu semakin berkembangan seiring degan perkembangan zaman. Salah satu di antara nya adalah perkembangan teknologi transportasi di kota-kota besar. Tetapi perkembangan teknologi bisa diibaratkan seperti pisau bermata dua. Perkembangan teknologi transportasi selain memberi dampak positif tetapi dapat menimbulkan juga dampak negatif. Salah satu dari dampak negatif perkembangan transportasi adalah meningkatnya jumlah volume kendaraan yang dapat menyebabkan masalah lalu lintas. Berdasarkan hasil survey BPS jumlah kendaraan tahun 2015 di yogyakarta sebanyak 279.359.

Lalu lintas merupakan media untuk berpindah dari suatu titik ke titik lain. Maka dari itu peran lalu lintas sangat penting dalam menunjang mobilitas kendaraan, apabila terjadi kemacetan maka mobilitas akan terhambat sehingga bisa memberi dampak negatif ke sektor-sektor lain. Masalah kemacetan sudah sangat sering terjadi di kotakota besar, hal ini disebabkan oleh beberapa hal, yaitu Jumlah penduduk yang terus 
bertambah, Jumlah kendaran pribadi yang terus naik, kondisi jalan raya parkir liar, dan kurang maksimal penggunaan transportasi umum serta faktor dari manusia nya itu sendiri. Seiring berjalannya waktu kondisi kemacetan semakin parah bukan semakin berkurang. Data mengenai jumlah kendaraan di Yogyakarta dapat dilihat pada Tabel 1.

Tabel 1. JumlahKendaraan di Yogyakarta (Sumber : BPS DIY)

\begin{tabular}{|c|c|c|c|c|}
\hline Jenis Kendaraan/ Type of Motorized Vehicles & $\begin{array}{c}\text { Bukan Umum Perorangan/ Non } \\
\text { Common Private } \\
\text { Transportation }\end{array}$ & $\begin{array}{l}\text { Umum Perusahaan/ } \\
\text { Common Private }\end{array}$ & $\begin{array}{l}\text { Pemerintah/ } \\
\text { Government }\end{array}$ & Jumlah/ Total \\
\hline Mobil Penumpang/ Passenger Car & 199858 & 3598 & 3202 & 206658 \\
\hline 1. Sedan/Sedan & 39471 & 1287 & 340 & 41098 \\
\hline 2. Station Wagon/Station Wagon & 30258 & 941 & 1255 & 3245 \\
\hline 3. Mini bus/Mini bus & 115676 & 1357 & 1370 & 118403 \\
\hline 4. Jeep/Jeep & 14453 & 13 & 237 & 14703 \\
\hline 5.Lain-lain/Others & - & - & - & \\
\hline Mobil Bus/Bus & 7553 & 3508 & 497 & 11558 \\
\hline 1. Bus Biasa/Bus & 232 & 2134 & 274 & 2640 \\
\hline 2. Mikro bus/Microbus & 7321 & 1374 & 223 & 8918 \\
\hline 3. Bus Tingkat/Three Step Bus & - & - & - & \\
\hline 4. Lain-lain/Others & - & - & - & \\
\hline Mobil Barang/Load Vehicles & 55357 & 4635 & 1151 & 61143 \\
\hline 1. Pick Up/Pick Up & 40733 & 1205 & 450 & 42388 \\
\hline 2. Van/Deliver Van & 224 & 14 & 1 & 239 \\
\hline 3.Truk Barang/Load Truck & 14162 & 3408 & 691 & 18261 \\
\hline 4. Truk Tank BBM/Air/ Tank of Water/Fuls & 170 & 1 & 1 & 172 \\
\hline 5. Double Cabin & 50 & 6 & 8 & \\
\hline 6. Lain-lain/others & 18 & 1 & - & \\
\hline
\end{tabular}

Menurut Salter (1989), hubungan antara lalu-lintas dengan tata guna lahan dapat dikembangkan melalui suatu proses perencanaan transportasi yang saling terkait, terdiri dari: (1) bangkitan/ tarikan perjalanan, untuk menentukan hubungan antara pelaku perjalanan dan faktor guna lahan yang dicatat dalam inventaris perencanaan; (2) penyebaran perjalanan, yang menentukan pola perjalanan antar zona; (3) pembebanan lalu lintas, yang menentukan jalur transportasi publik atau jaringan jalan suatu perjalanan yang akan dibuat; dan (4) pemilihan moda, suatu keputusan yang dibuat untuk memilih moda perjalanan yang akan digunakan oleh pelaku perjalanan.

Telah banyak riset menggunakan metode FCM C-Means dan aplikasi untuk mendeteksi kemacetan, antara lain riset yang serupa dengan riset ini adalah riset tentang pengembangan aplikasi bergerak untuk mendeteksi tingkat kemacetan lalu lintas dan cuaca di yogyakarta dengan memanfaatkan Google MapsAPI, open weatther map API dan GPS yang dilakukaan oleh Taufiq El Rahman pada Tahun 2014. Ardan (2012) melakukan riset yang serupa yaitu analisis kepadatan lalu lintas menggunakan metode SVM dan ICA.

Berdasarkan Manual KapasitasJalan Indonesia (MKJI) 1997, DirektoratJenderal Bina Marga Direktorat Bina Jalan Kota, Volume lalu-lintas ruas jalan adalah jumlah atau banyaknya kendaraan yang melewati suatu titik tertentu pada ruas jalan dalam suatu satuan waktu tertentu. Volume lalu-lintas dua arah pada jam paling sibuk dalam sehari dipakai sebagai dasar untuk analisis unjuk kerja ruas jalan dan persimpangan yang ada. Untuk kepentingan analisis, kendaran yang disurvey dikasifikasikan atas: (1) kendaraan 
ringan (Light Vehicle/LV) yang terdiri dari Jeep, Station Wagon, Colt, Sedan, Bis mini, Combi, Pick Up, dan sebagainya; (2) kendaraan berat (Heavy Vehicle/ HV), terdiri dari Bus dan Truk; dan (3) sepeda motor (Motorcycle/MC).

\section{METODE}

Metode analisis yang digunakan diawali dengan pengumpulan data jumlah kendaraan dan data terkait lainnya di Dinas Perhubungan DIY. Data yang dikumpulkan merupakan data Volume dan Kapasitas dari Jalan Adisucipto. Data tersebut selanjutnya dijadikan dasar untuk melakukan analisis time series.

Analisis time series merupakan sebuah metode forecasting (peramalan) berdasarkan variabel data secara berurutan. Metode trend merupakan salah satu metode yang sering digunakan dalam forecasting. Secara umum metode trend dirumuskan sebagai berikut:

$$
y=a+b t
$$

\author{
Keterangan: \\ y: data time series yang akan \\ diperkirakan \\ t: variabel waktu \\ a: konstanta \\ b: koefisien
}

Lebih lanjut lagi, $a$ dan $b$ didapat dengan menggunakan formula:

$$
\begin{gathered}
a=y-b t \ldots . .(2) \\
y=\frac{\sum y}{n} \operatorname{dan} t=\frac{\sum t}{n} \ldots . . \\
b=\frac{\sum t y-\frac{\sum t \sum y}{n}}{\sum t^{2}-\frac{\left(\sum t\right)^{2}}{n}} \ldots . .
\end{gathered}
$$

Analisis VCR merupakan suatu metode untuk membandingkan antara Volume kendaraan dengan Kapasitas Jalan tersebut.

\begin{tabular}{|c|c|c|c|}
\hline Nilai VCR & Kelas & Kondisi & Keterangan \\
\hline $0.00-0.20$ & $\mathrm{~A}$ & $\begin{array}{l}\text { Kondisi arus lalu lintas bebas dengan kecepatan } \\
\text { tinggi dan volume lalu lintas rendah }\end{array}$ & Sangat Stabil \\
\hline $0.20-0.44$ & B & $\begin{array}{c}\text { Arus stabil, tetapi kecepatan operasi mulai dibatasi } \\
\text { oleh kondisi lalu lintas }\end{array}$ & Hampir stabil \\
\hline $0.45-0.74$ & $\mathrm{C}$ & $\begin{array}{c}\text { Arusstabil, tetapi kecepatan dan gerak kendaraan } \\
\text { dikendalikan }\end{array}$ & Stabil \\
\hline $0.75-0.84$ & $\mathrm{D}$ & $\begin{array}{l}\text { Arus mendekati stabil, kecepatan masih dapat } \\
\text { dikendalikan. V/C masih dapat ditolerir }\end{array}$ & Hampir macet \\
\hline $0.85-1.00$ & $\mathrm{E}$ & $\begin{array}{l}\text { Arus tidak stabil kecepatan terkadang terhenti, } \\
\text { permintaan sudah mendekati kapasitas }\end{array}$ & Buruk \\
\hline$>1$ & F & $\begin{array}{l}\text { Arus dipaksakan, kecepatan rendah, volume } \\
\text { diataskapasitas, antrian panjang (macet) }\end{array}$ & Sangat Buruk \\
\hline
\end{tabular}
Ketentuan dari nilai VCR ditunjukan pada Tabel 2.

Tabel 4. Nilai VCR (Sumber MKJI) 
HASIL

Hasil pengumpulan data berupa Volume dan Kapasitas dari Jalan Adisucipto yang diperoleh selanjutnya di klasifikasikan kedalam tiga kelompok, yaitu: (1) MC untuk sepeda motor; (2) LV untuk kendaraan ringan; dan (3) HV untuk kendaraan berat. Data dimasukkan perdasarkan periode waktu tertentu dari dua arah jalan yang berlawanan. Hasil pengklasifikasian jumlah kendaraan di Jalan Adisucipto depan Ambarukmo Plaza dapat dilihat pada Tabel 3.

Tabel 3. Data jumlah kendaraan di Jalan Adisucipto depan Ambarukmo Plaza (Sumber Dishub DIY)

\begin{tabular}{|c|c|c|c|c|c|c|c|c|c|}
\hline \multirow{3}{*}{ Periode Waktu } & \multicolumn{8}{|c|}{ Arus (smp/jam) } & \multirow[t]{3}{*}{ Total } \\
\hline & \multicolumn{4}{|c|}{ Arah 1} & \multicolumn{4}{|c|}{ Arah 2} & \\
\hline & $\mathrm{MC}$ & LV & HV & Total & MC & LV & $\mathrm{HV}$ & Total & \\
\hline $06.30-06.45$ & 1122 & 1100 & 13 & 2235 & 1768 & 1202 & 18 & 2988 & 5223 \\
\hline $06.45-07.45$ & 1082 & 1123 & 13 & 2218 & 1838 & 1202 & 23 & 3063 & 5281 \\
\hline $07.00-08.00$ & 1070 & 1162 & 13 & 2245 & 1837 & 1183 & 28 & 3048 & 5293 \\
\hline $07.15-08.15$ & 1028 & 1214 & 25 & 2267 & 1743 & 1153 & 30 & 2926 & 5193 \\
\hline $07.30-08.30$ & 985 & 1216 & 30 & 2231 & 1676 & 1114 & 28 & 2818 & 5049 \\
\hline $09.00-10.00$ & 762 & 1167 & 29 & 1958 & 955 & 1170 & 41 & 2166 & 4124 \\
\hline $09.15-10.15$ & 776 & 1375 & 35 & 2186 & 943 & 1204 & 46 & 2193 & 4379 \\
\hline $09.30-10.30$ & 815 & 1567 & 32 & 2414 & 962 & 1228 & 40 & 2230 & 4644 \\
\hline $09.45-10.45$ & 839 & 1688 & 34 & 2561 & 1029 & 1223 & 35 & 2287 & 4848 \\
\hline $10.00-11.00$ & 892 & 1847 & 32 & 2771 & 1109 & 1253 & 35 & 2397 & 5168 \\
\hline $15.30-16.30$ & 1974 & 3243 & 40 & 5257 & 1053 & 1043 & 18 & 2114 & 7371 \\
\hline $15.45-16.45$ & 1949 & 3085 & 55 & 5089 & 1089 & 1066 & 22 & 2177 & 7266 \\
\hline $16.00-17.00$ & 1836 & 2677 & 53 & 4566 & 1092 & 1054 & 25 & 2171 & 6737 \\
\hline $16.15-17.15$ & 1697 & 2407 & 46 & 4150 & 1123 & 1054 & 28 & 2205 & 6355 \\
\hline $16.30-17.30$ & 1587 & 2151 & 40 & 3778 & 1160 & 1085 & 26 & 2271 & 6049 \\
\hline
\end{tabular}

Berdasarkan Tabel 3, terlihat bahwa periode waktu terbagi antara pukul 06.30 sampai dengan 08.30, 09.00 sampai dengan 11.00 dan 15.30 sampai dengan 17.30 . Terdapat periode waktu yang belum terdata jumlah kendaraan yang melalui Jalan Adisucipto depan Ambarukmo Plaza. Jalan Adisucipto depan Ambarukmo Plaza sendiri merupakan jalan yang dipilih dikarenakan penggunaan lahan untuk pembangunan Ambarukmo Plaza sebagai tempat berbelanja sekaligus untuk makan dan menonton bioskop ditengah kota Yogyakarta. Jalan tersebut merupakan jalur transportasi yang dekat dengan berbagai fasilitas pendidikan dan kesehatan, serta berada di Jalan penghubung yang dilalui banyak pengguna jalan antarkota, 
baik sebagai pelajar/ mahasiswa maupun pekerja/ karyawan.

Tabel 3 menunjukkan bahwa kendaraan berat merupakan jenis kendaraan yang paling sedikit melewati jalan tersebut. Adanya perbedaan jumlah sepeda motor dan kendaraan ringan pada tiap periode dapat menunjukkan pola perjalanan dari para pengguna kendaraan. Untuk periode pagi hari (06.30 sampai dengan 08.30) kecenderungan dari arah 2 lebih padat dari arah 1 . Kecenderungan tersebut semakin terlihat pada periode waktu kedua yaitu 09.00 sampai dengan 11.00. Sebaliknya, pada periode sore hari (15.30 sampai dengan 17.30) kecenderungan dari arah 1 yang lebih padat dari arah 2.

Pada artikel ini, jumlah kendaraan pada periode waktu (12.30 sampai dengan 14.30) yang belum terdata tersebut menjadi data yang dianalisis. Analisis time series dengan metode trend digunakan untuk melakukan forecasting. Hasil forecasting dapat dilihat pada Tabel 4.

Tabel 4. Tabel hasil forecasting

\begin{tabular}{|c|c|c|c|c|c|c|c|c|c|}
\hline \multirow{2}{*}{$\begin{array}{l}\text { Peri- } \\
\text { ode }\end{array}$} & \multirow{2}{*}{ jam } & $\mathrm{Yt}$ & smooth & center & $\begin{array}{c}\mathrm{Y}_{\mathrm{t}} / \\
\mathrm{CMA}\end{array}$ & $\mathrm{S}_{\mathrm{t}}$ & $\mathrm{Y}_{\mathrm{t}} / \mathrm{S}_{\mathrm{t}}$ & $\mathrm{Tt}$ & \multirow{2}{*}{$\begin{array}{l}\text { Fore- } \\
\text { casting }\end{array}$} \\
\hline & & motor & MA(4) & $\begin{array}{c}\text { CMA } \\
\text { (4) }\end{array}$ & $\mathrm{S}_{\mathrm{t}} \cdot \mathrm{I}_{\mathrm{t}}$ & & $\begin{array}{c}\text { Desea- } \\
\text { sonalize }\end{array}$ & & \\
\hline \multirow[t]{5}{*}{1} & $06.30-06.45$ & 1122 & & & & 0.89 & 1257.91 & 1158.57 & 1033 \\
\hline & $06.45-07.45$ & 1082 & & & & 0.94 & 1151.86 & 1108.31 & 1041 \\
\hline & $07.00-08.00$ & 1070 & 1057.4 & 1021.4 & 1.05 & 1.05 & 1021.40 & 1058.05 & 1108 \\
\hline & $07.15-08.15$ & 1028 & 985.4 & 954.8 & 1.08 & 1.08 & 951.85 & 1007.80 & 1088 \\
\hline & $07.30-08.30$ & 985 & 924.2 & 898.7 & 1.10 & 1.1 & 895.45 & 957.54 & 1053 \\
\hline \multirow[t]{5}{*}{2} & $09.00-10.00$ & 762 & 873.2 & 854.3 & 0.89 & 0.89 & 856.18 & 907.29 & 807 \\
\hline & $09.15-10.15$ & 776 & 835.4 & 826.1 & 0.94 & 0.94 & 825.53 & 857.03 & 806 \\
\hline & $09.30-10.30$ & 815 & 816.8 & & & 1.05 & 776.19 & 806.77 & 847 \\
\hline & $09.45-10.45$ & 839 & & & & 1.08 & 776.85 & 756.52 & 817 \\
\hline & $10.00-11.00$ & 892 & & & & 1.1 & 810.91 & 706.26 & 777 \\
\hline \multirow[t]{5}{*}{3} & $12.30-13.30$ & & & & & 0.89 & & 656.00 & 584 \\
\hline & $12.45-13.45$ & & & & & 0.94 & & 605.75 & 569 \\
\hline & $13.00-14.00$ & & & & & 1.05 & & 555.49 & 583 \\
\hline & $13.15-14.15$ & & & & & 1.08 & & 505.23 & 546 \\
\hline & $13.30-14.30$ & & & & & 1.1 & & 454.98 & 500 \\
\hline
\end{tabular}

Analisis data time series menggunakan data jumlah motor sebagai contoh. Berdasarkan hasil Tabel 3 dan Gambar 1, dapat diketahui bahwa jumlah kendaraan mengalami penurunan jumlah mulai dari pukul
12.30 sampai dengan pukul 14.30 . Hal tersebut terjadi karena pada siang hari pengguna jalan jarang melakukan aktifitas di jalanan, sehingga mengurangi volume kendaraan. 


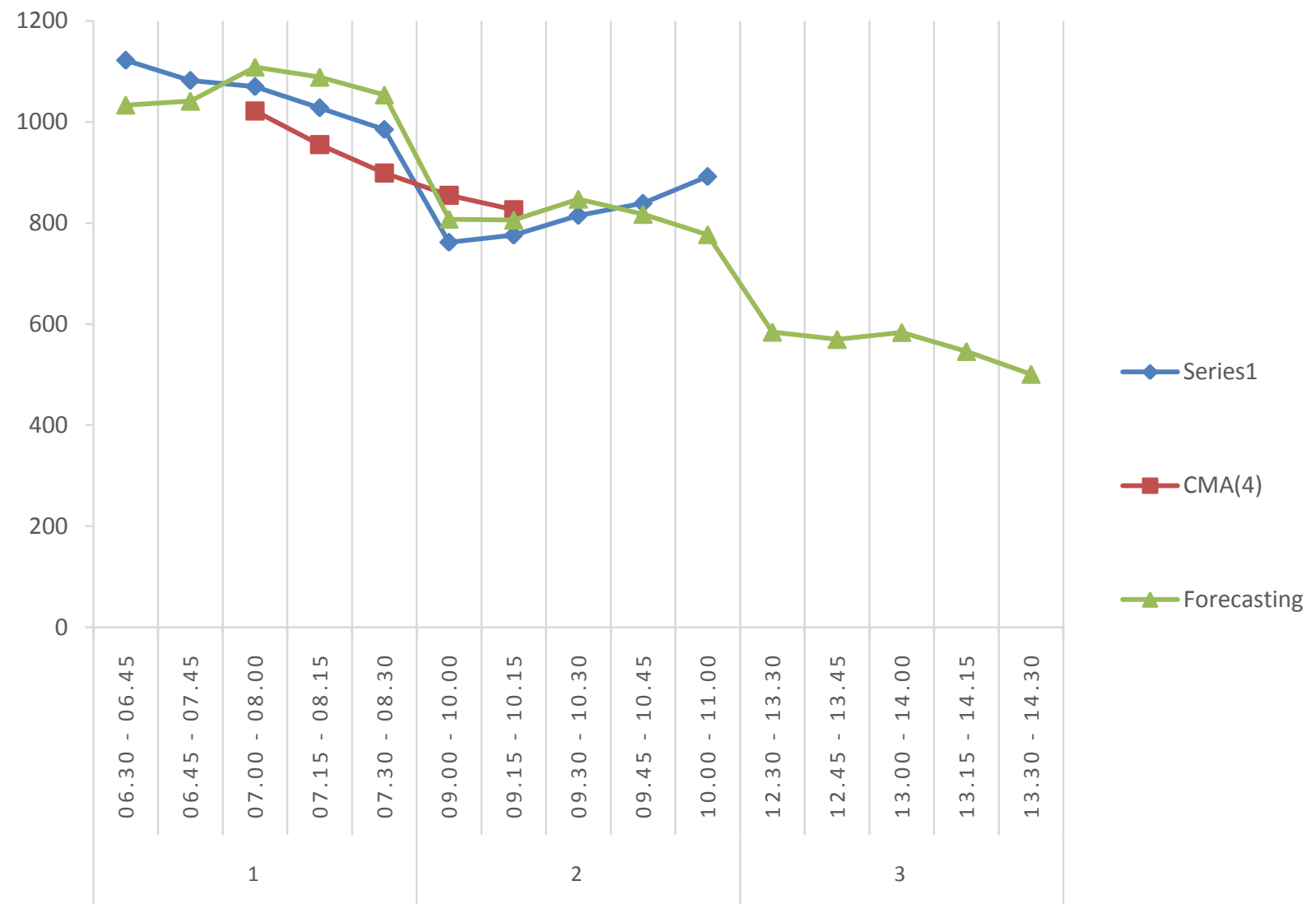

Gambar 1. Grafik Hasil Forecasting

Volume kendaraan dengan Kapasitas Jalan dibandingkan menggunakan metode analisis VCR. Tabel 5 menunjukkan hasil analisis VCR yang dapat menunjukkan kondisi kestabilan arus lalu lintas pada Jalan Adisucipto depan Ambarukmo Plaza.

Tabel 5. Hasil Analisis VCR

Arus (smp/jam)

Periode Waktu

Arah 1

Arah 2

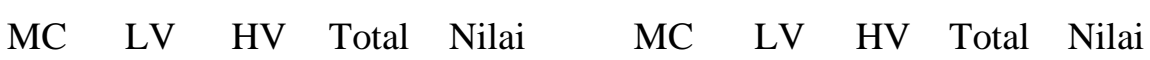

Total

VCR VCR

\begin{tabular}{lccccccccccc}
$06.30-06.45$ & 1122 & 1100 & 13 & 2235 & 0.53 & 1768 & 1202 & 18 & 2988 & 0.70 & 5223 \\
$06.45-07.45$ & 1082 & 1123 & 13 & 2218 & 0.52 & 1838 & 1202 & 23 & 3063 & 0.72 & 5281 \\
$07.00-08.00$ & 1070 & 1162 & 13 & 2245 & 0.53 & 1837 & 1183 & 28 & 3048 & 0.72 & 5293 \\
$07.15-08.15$ & 1028 & 1214 & 25 & 2267 & 0.53 & 1743 & 1153 & 30 & 2926 & 0.69 & 5193 \\
$07.30-08.30$ & 985 & 1216 & 30 & 2231 & 0.52 & 1676 & 1114 & 28 & 2818 & 0.66 & 5049 \\
& & & & & & & & & & & \\
$09.00-10.00$ & 762 & 1167 & 29 & 1958 & 0.46 & 955 & 1170 & 41 & 2166 & 0.51 & 4124 \\
$09.15-10.15$ & 776 & 1375 & 35 & 2186 & 0.51 & 943 & 1204 & 46 & 2193 & 0.52 & 4379 \\
$09.30-10.30$ & 815 & 1567 & 32 & 2414 & 0.57 & 962 & 1228 & 40 & 2230 & 0.52 & 4644 \\
$09.45-10.45$ & 839 & 1688 & 34 & 2561 & 0.60 & 1029 & 1223 & 35 & 2287 & 0.54 & 4848 \\
$10.00-11.00$ & 892 & 1847 & 32 & 2771 & 0.65 & 1109 & 1253 & 35 & 2397 & 0.56 & 5168 \\
\hline
\end{tabular}


Arus (smp/jam)

\begin{tabular}{ccccccccccccc} 
Periode Waktu & \multicolumn{1}{c}{ Arah 1 } & \multicolumn{1}{c}{ Arah 2 } \\
& MC & LV & HV & Total & $\begin{array}{c}\text { Nilai } \\
\text { VCR }\end{array}$ & MC & LV & HV & Total & $\begin{array}{c}\text { Nilai } \\
\text { VCR }\end{array}$ \\
\hline & & & & & & & & & & & & \\
$15.30-16.30$ & 1974 & 3243 & 40 & 5257 & 1.23 & 1053 & 1043 & 18 & 2114 & 0.50 & 7371 \\
$15.45-16.45$ & 1949 & 3085 & 55 & 5089 & 1.20 & 1089 & 1066 & 22 & 2177 & 0.51 & 7266 \\
$16.00-17.00$ & 1836 & 2677 & 53 & 4566 & 1.07 & 1092 & 1054 & 25 & 2171 & 0.51 & 6737 \\
$16.15-17.15$ & 1697 & 2407 & 46 & 4150 & 0.97 & 1123 & 1054 & 28 & 2205 & 0.52 & 6355 \\
$16.30-17.30$ & 1587 & 2151 & 40 & 3778 & 0.89 & 1160 & 1085 & 26 & 2271 & 0.53 & 6049 \\
\hline
\end{tabular}

Hasil analisis VCR pada Tabel 5 menunjukan bahwa kendaraan di Jalan Adisucipto depan Ambarukmo Plaza mencapai puncaknya pada pukul $15.30-17.00$ khususnya dari arah 1 dengan perolehan skor nilai VCR sebesar 1,23 yang termasuk kelas $F$ (sangat buruk) yaitu dengan kondisi Arus dipaksakan, kecepatan rendah, volume diatas kapasitas, antrian panjang (macet). Pada periode waktu 15.30 sampai dengan 17.30 tersebut kondisi arus lalu lintas untuk arah 1 cenderung sangat buruk dan berangsur menurun pada kondisi buruk. Hal tersebut dikarenakan jumlah kendaraan sangat besar pada periode waktu tersebut. Moda transportasi pada periode waktu 15.30-17.30 pada masing-masing jenis kendaraan merupakan jumlah yang paling besar diantara periode waktu lainnya. Periode waktu tersebut merupakan periode waktu berakhirnya jam kerja di satu institusi/ badan usaha/ perkantoran. Beberapa hal terkait temuan tersebut apabila disesuaikan dengan pernyataan Salter (1989) terkait perencaan transportasi, hubungan lalu lintas dengan tata guna lahan adalah bangkitan perjalanan (pelaku perjalanan dan faktor guna lahan), pola perjalanan, pembebanan lalu lintas dan pemilihan moda transportasi.

Dilain pihak, pada waktu yang bersamaan dari arah 2, lalu lintas cenderung pada keadaan stabil yaitu kecepatan dan gerak kendaraan dapat dikendalikan. Hal tersebut terindikasi dari perolehan skor nilai VCR antara 0,50 sampai dengan 0,53 yang termasuk pada kelas C (stabil). Untuk periode waktu lainnya, baik dari arah 1 maupun arah 2 menunjukkan bahwa arus lalu lintas pada kedua arah tersebut di Jalan Adi Sucipto depan Ambarukmo Plaza cenderung stabil.

\section{SIMPULAN}

Berdasarkan analisis data time series menggunakan metode trend, data jumlah motor yang melalui Jalan Adisucipto pada pukul 12.30-14.40 cenderung mengalami penurunan, hal ini terjadi karena pada siang hari penduduk jarang melakukan aktifitas di jalanan, sehingga mengurangi volume kendaraan. Berdasarkan analisis VCR, jumlah kendaraan mencapai puncaknya pada pukul 15.30-17.00 dan termasuk pada kelas F (sangat butuk), yaitu kondisi arus dipaksakan, kecepatan rendah, volume diatas kapasitas dan antrian panjang (macet) khususnya dari arah 1 . Hal tersebut disebabkan pada sore hari merupakan jam pulang kantor bagi karyawan dan mahasiswa, sehingga menambah jumlah volume kendaraan di jalan tersebut.

\section{DAFTAR PUSTAKA}

Ignatia Yolanda, Kartono, Sunarsih. 2011. Analisis Kepadatan Lalu Lintas di Perlimaan Jalan (studi kasus di jalan soekarnohatta-tlogosari-supriyadimedoho).

Julia Veronica. 2014. Analisis Tingkat Kepadatan Lalu Lintas di kecamatan denpasar barat. 
Manual Kapasitas Jalan Indonesia (MKJI). 1997. Jakarta: Direktorat Jendral Bina Marga, Departement Pekerjaan Umum Nugroho Eko, J. 2010. Hubungan Antara Kecepatan, Volume, dan KepadatanLalu Lintas. Jurnal Jurusan Teknik Sipil Universitas Negeri Semarang. 2010

Purwanto, Heri. 1997. Aplikasi Graf Kompatibilitas Jalan Pada Penentuan Arus Lalu Lintas di Perempatan Jalan. Skripsi Semarang: Program Matematika Universitas Diponegoro.

Taufiq El Rahman, I WayanMustika. 2014. Pengembangan Aplikasi Bergerak untuk Mendeteksi Tingkat Kemacetan Lalu Lintas dan Cuaca Memanfaatkan Google Maps API, OpenWeatherMap API, dan GPS. UGM. Yogyakarta.

Widodo. Wahyu. 2012. Analisis Volume, Kecepatan, dan kepadatan Lalu Lintas dengan Metode Greenshields dan Greenberg,. Jurnal Ilmiah Semesta Teknika.

Yulia servita, Shinta. 2009. Analisa Kepadatan Lalulintas Menggunakan Support Vektor Machine, IT Telkom, Bandung. 